\title{
Effect of Surgical Complications on Quality of Life after Thoracoscopic Lobectomy for Lung Cancer
}

\author{
Sayf Gazala1,2, Jeffrey A. Johnson², James D. Kutsogiannias ${ }^{3}$, Eric L. R. Bédard1 ${ }^{*}$ \\ ${ }^{1}$ Department of Surgery, University of Alberta, Edmonton, Canada \\ ${ }^{2}$ School of Public Health, University of Alberta, Edmonton, Canada \\ ${ }^{3}$ Department of Medicine, University of Alberta, Edmonton, Canada \\ Email: gazala@ualberta.ca
}

Received 3 January 2014; revised 3 February 2014; accepted 10 February 2014

Copyright (C) 2014 by authors and Scientific Research Publishing Inc.

This work is licensed under the Creative Commons Attribution International License (CC BY). http://creativecommons.org/licenses/by/4.0/

(c) (i) Open Access

\section{Abstract}

Background: Surgical resection is the main treatment for early stage lung cancer; the benefits of surgery, however, need to be weighed against possible complications and patients' quality of life. Methods: We performed a cohort study following patients after video assisted thoracoscopic lobectomy at our tertiary care center. Before surgery, health related quality of life was assessed using the SF-36, the QLQ30, QLQ13 and EQ5D questionnaires. Post-operatively health related quality of life was assessed at regular intervals $(2,4,8$ and 12 weeks). A research team assessed post-operative complications on a daily basis during the patients' hospital stay. Based on the Clavien classification system, the cohort was classified as experiencing high-grade (i.e., grade III or IV) complications or not. Changes in quality of life scores over the follow-up period were compared using linear regression with generalized estimating equations. Results: Between March and September 2011, 44 eligible patients were recruited into the study. The mean age was 65 (SD 8.7) years; $55 \%$ were male. The majority $(n=31 ; 71 \%)$ had no or low-grade complications. Patients experiencing high-grade complications reported significantly worse outcomes in the following domains of the SF-36: Global Health, Vitality, and Physical Functioning ( $p<0.05$ for all). On the QLQ 30 and QLQ 13, patients with high-grade complications had worse outcomes in the dyspnea, emotional function and cognitive function scales, as well as worse shoulder and chest pain, and financial difficulties ( $p<0.05$ for all). Conclusions: The severity of post-operative complications after video assisted thoracoscopic lobectomy negatively impacts patient centered outcomes postoperatively.

\footnotetext{
${ }^{*}$ Corresponding author.
} 
Keywords

VATS; Quality of Life; Lung Cancer Surgery

\section{Background}

Patients with lung cancer have lower health-related quality of life (HRQOL) when compared to the general population and to patients with other malignancies (e.g., breast, prostate and colon) [1]. Anatomical surgical resection, in the form of segmentectomy, lobectomy or pneumonectomy, represents the mainstay of treatment for early stage non-small cell lung cancer (NSCLC) [2]. While HRQOL declines following surgical resection of NSCLC, it has been shown to return to baseline function in a period of three to twelve months after surgery, depending on patient condition at baseline, extent of surgical resection, the presence of severe dyspnea and the need for adjuvant therapy post-operatively [3]-[5].

Post-operative complications are commonly used for the assessment of quality of care in surgical practice [6] [7] and may also have an important role in functional recovery and HRQOL for patients undergoing surgical resection for lung cancer. Major post-operative complications have been reported with VATS lobectomy [8], however, to our knowledge, no studies have addressed the impact of post-operative complications after lung cancer resection on patients' reported outcomes, and the effect it can have on recovery from surgery and return to baseline function and activates, and HRQOL in patients who might require further treatment in the form of chemotherapy. The Clavien surgical complication classification system has recently been validated in patients undergoing different thoracic surgery procedures [6].

The objective of this study is to assess the influence of post-operative complications on the HRQOL of patient undergoing Video Assisted Thoracoscopic (VATS) lobectomy for NSCLC.

\section{Methods and Materials}

Approval for this study was obtained from the University of Alberta Human Ethics Board.

The Royal Alexandra Hospital is a tertiary care center for thoracic surgery, serving a population of over 2 million. All adult oncologic thoracic procedures are performed at this site. All four thoracic surgeons performing Video Assisted Thoracoscopic Surgery (VATS) for lung cancer participated in the study.

All patients who were referred to the thoracic surgery oncology clinic and assessed by one of the four surgeons were reviewed by one of the study investigators (S.G). Those who were found to have a potentially resectable non-small cell lung carcinoma via the VATS lobectomy approach were considered eligible for the study. Exclusion criteria were: age less than 18 years, inability to speak English, hearing problems, speaking problems, inability to undergo the VATS approach, metastatic cancer to the lung and patients who could not tolerate anatomical resection (Figure 1). The CONSORT flow chart for patients' enrollment in the study.

A research nurse recruited the potential patients during their Pre-Admission Clinic (PAC) visit. Patients who agreed to participate in the study had the baseline HRQOL questionnaires (see HRQOL Measures below) completed at the same day in a face-to-face interview.

The post-operative period was categorized as "early" focusing on the first three months after the anatomical pulmonary resection. We scheduled patient interviews at regular intervals after surgery to capture the changes and their occurrence in this time period. The regular intervals were decided a priori as the following; the first follow up was at two weeks ( $+/-2$ days), as a phone interview. The second follow up was at four weeks $(+/-3$ days), as a face-to-face interview. The third follow up was at eight weeks ( $+/-3$ days), as a phone interview. The fourth and final follow up was at three months (+/- 7 days), as a face-to-face interview. The day of surgical resection was considered as time point zero. To prevent patient fatigue and maximize the retention of patients in the study during the post-operative period, specific questionnaires were to be completed at each follow up interview.

Following surgery, all patients were assessed on a daily basis during their hospital stay, by the researchers (independent from the clinical treatment team) to identify all the post-operative complications and the treatments implemented for them. 


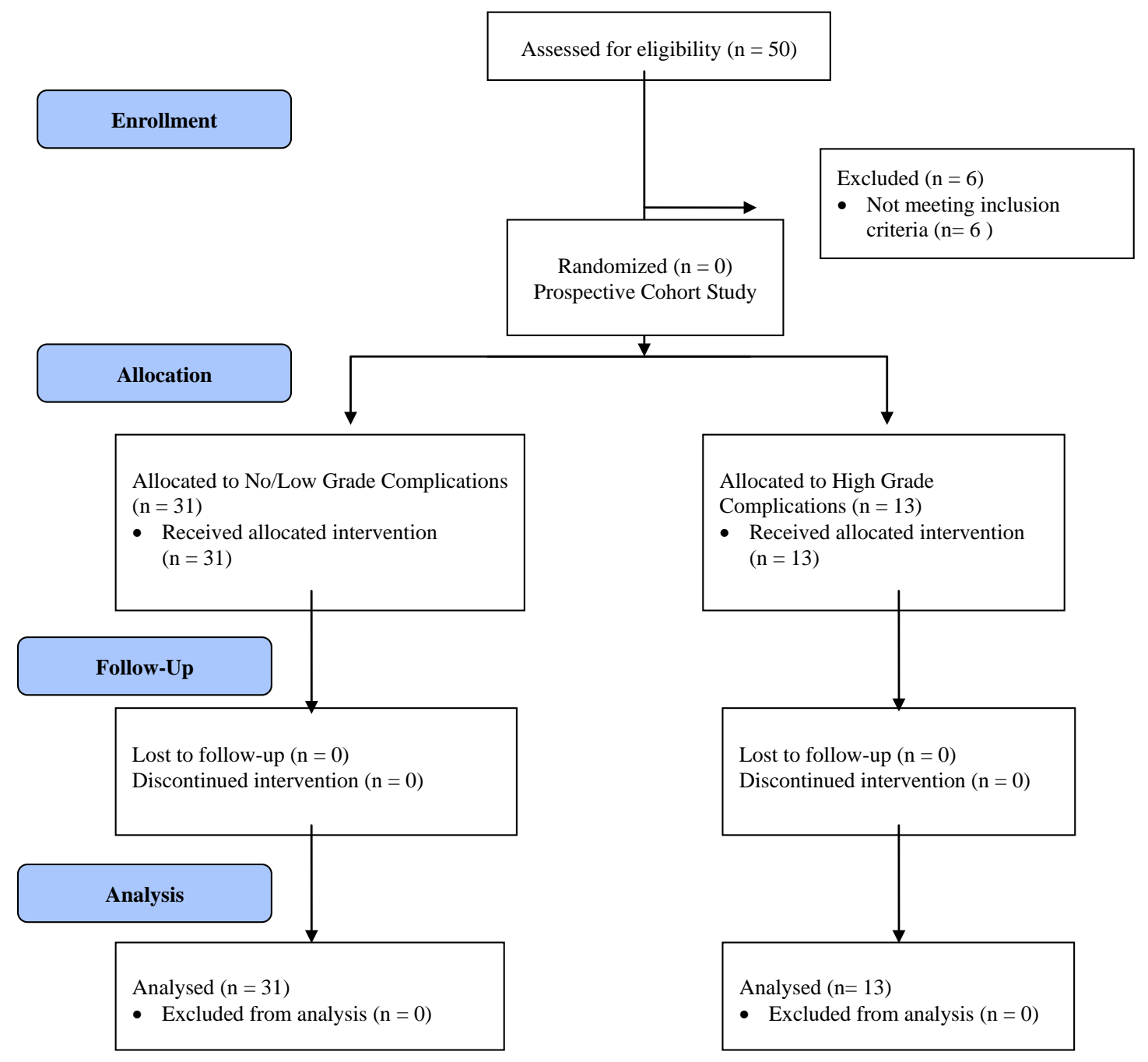

Figure 1. The CONSORT flow chart.

\subsection{HRQOL Measures}

The baseline HRQOL questionnaires included are the Medical Outcomes Study Short Form-36 (SF-36) version 2, the European Organization for Research and Treatment of Cancer (EORTC) Quality of Life Questionnaire (QLQ) 30, the EORTC QLQ 13 and the utility index EQ-5D. The rationale for using multiple measures is to determine which HRQOL assessment tool will be most useful to be used in the future for patients undergoing lung resections for cancer. These measures were administered by the same research person and at the same sequence every time.

The SF-36 health survey is a generic measure commonly used in HRQOL assessment both in the general population and the thoracic surgical population; it is generally regarded as a valid and reliable measure [9]-[11]. The SF-36 is a brief and simple questionnaire that contains 36 items covering 8 health domains. The eight domains assessed by the SF-36 are the following: Physical Functioning, Role Limitation-Physical, Role Limitation-Emotional, Bodily Pain, Vitality, Social Functioning, Mental Health and General Health. Each domain will have a score between 0 and 100, where higher scores indicate better HRQOL. The RAND scoring system was used to score the SF-36 health survey. The RAND scoring system uses the oblique factor correlation method to construct the physical and mental component scores [12].

EORTC has developed and validated the cancer specific questionnaire QLQ 30. The QLQ 30 has thirty questions covering five multi-item functional scales (Physical functioning, Emotional Functioning, Role Functioning, Social Functioning and Cognitive Functioning), and 6 single-item symptom scales [13]. The QLQ 13 is a lung 
cancer specific module that can be added to the QLQ 30. The thirteen questions of the QLQ 13 will yield one symptom scale (dyspnea scale) and ten single-item symptom scales [13]. The QLQ 30 and QLQ 13 are both scored the same way, with a final score of 0 to 100 , where 100 indicate the best possible health status in the functional scales while 0 represent the best possible health status in the symptom scales [13].

The EQ-5D is a widely used utility index that measures 5 health dimensions (Mobility, Self Care, Usual Activities, Pain and Anxiety/Depression) and current health state using a visual analogue scale (VAS). Each of the five dimensions has three levels of functioning (no problem, moderate problem and extreme problem), yielding 243 unique health states. An EQ-5D utility index can be produced, based on time-trade off valuations, anchored at 0 and 1, indicating dead and perfect health, respectively [14]. The US (D1) scoring function was used for calculating the index score for the EQ-5D [15] [16].

\subsection{Surgical Procedure}

All the patients included were candidates for VATS lobectomy. VATS lobectomy was performed using three incisions; one $2 \mathrm{~cm}$ incision in the anterior $6^{\text {th }}$ interspace at the level of the costal margin, one $5 \mathrm{~mm}$ incision in posterior axillary line of the $8^{\text {th }}$ interspace for a 30-degree $5 \mathrm{~mm}$ thoracoscope and one $5 \mathrm{~cm}$ utility incision located in the fourth intercostal space between the angle of the scapula and the breast anterior to the latissimus dosri muscle. A fourth incision in the paravertebral line of the $8^{\text {th }}$ interspace is used for lung retraction during upper lobectomies. The procedure is performed without rib spreading and involves individual hilar dissection and ligation of the lobar blood vessels and the bronchus with lymph nodes sampling or dissection at the discretion of the surgeon.

\subsection{The Clavien Classification}

The Clavien classification is a scoring system used for classification of post-operative complications based on the intervention required for the treatment of a specific complication. The Clavien classification has 5 grades; grade one is any deviation from normal, grade two is when you require simple medication intervention or the administration of blood or blood products. In grade three, a surgical intervention is required, while in grade four there is an organ failure that necessitate ICU or CCU admission. Grade five includes post-operative mortality. The suffix "d" is added when a patient is discharged home with disability [7].

\subsection{Statistical Analysis}

The sample size estimate was based on the SF-36 domains using a clinically minimal importance difference of $0.5 \mathrm{SD}$, the use of $0.5 \mathrm{SD}$ as a determinant of clinically minimal important difference is validated in HRQOL research for sample size calculations [17]. The SD of the sample was determined based on norms values from the Canadian population. We determined that 38 patients undergoing VATS lobectomy would provide $80 \%$ power (2-tailed $\alpha$ error probability 5\%) to detect the above-mentioned difference, in all the eight domains of the SF-36 questionnaire.

STATA data analysis and statistical software, Version 12, was used for the data analysis. A multiple linear regression with Generalized Estimating Equations (GEE) method (exchangeable correlation) was used to assess the difference over the follow up time in HRQOL measured by every domain, scale, and symptom of all the questionnaires compared to HRQOL at baseline between the high complication group and no/low complication group. All regression models were adjusted for age and sex.

\section{Results}

Forty-four patients were included in the study and completed the follow up (No patients were lost to follow up). Thirty-one of the patients had no complications or low-grade complications (grade one and two as defined by the Clavien classification system) and thirteen patients had high-grade complications (grade three, four or discharged home with disability). The characteristics of patients involved in the study are shown in Table 1. Pulmonary function tests and comorbidities were of no difference between the two groups. All the patients had to be active to be included in the study (no hearing and visual problems, and able perform a 6 minute walk test). Three patients (two in the low grade complications group) had conversion from VATS to an anterolateral thoracotomy and these patients were included in final analysis. 
Table 1. Patients demographics by complications group.

\begin{tabular}{|c|c|c|c|}
\hline & No/Low grade complications & High grade complications & $p$ value \\
\hline Total number & 31 & 13 & \\
\hline Age (years) & $64.8 \pm 9.1$ & $66.3 \pm 7.3$ & $\mathrm{NS}^{*}$ \\
\hline Sex M:F & $18: 13$ & $6: 7$ & $\mathrm{NS}^{*}$ \\
\hline Stage IA & 17 & 7 & $\mathrm{NS}^{*}$ \\
\hline Stage IB & 8 & 5 & $\mathrm{NS}^{*}$ \\
\hline Stage IIA & 2 & 1 & $\mathrm{NS}^{*}$ \\
\hline Stage IIB & 3 & 0 & $\mathrm{NS}^{*}$ \\
\hline Stage IIIA & 1 & 0 & $\mathrm{NS}^{*}$ \\
\hline Chest tube duration (days) & $3.2 \pm 2.1$ & $8.4 \pm 4.4$ & $\mathrm{p}<0.01$ \\
\hline Length of stay (days) & $4.3 \pm 2.4$ & $9.7 \pm 6.1$ & $\mathrm{p}<0.01$ \\
\hline
\end{tabular}

Not significant $(\mathrm{p}>0.05)$.

In the No/Low complication group, twenty patients had no complications and eleven patients had Grade I or II complications. The low-grade complications included: atrial fibrillation, pneumonia, electrolyte disturbances, blood transfusion and atelectasis. Thirteen patients had high-grade complications or were discharged home with disabilities. The high-grade complications encountered during the hospital stay were; Redo VATS for bleeding, bronchoscopy for severe atelectasis, chest tube re-insertion, ICU admission, and discharge home with a Heimlich valve. Two patients required a repeat VATS for bleeding, one had an intercostal bleeding and the other person was found to have hemothorax without an identified source of bleeding. Three patients needed chest tube reinsertion for pneumothorax in one patient and extensive subcutaneous emphysema in the other two. Respiratory failure accounted for all the three ICU admissions that required mechanical ventilation for a period between 2 - 4 days.

\subsection{HRQOL Measured by the SF-36}

At the end of twelve weeks after VATS lobectomy patients with high-grade complications had lower HRQOL measured in all the eight domains of the SF-36, except social functioning which was similar to the low complication group (Table 2). The differences were statistically significant in three domains, namely: General Health, Vitality and Mental Health (p value < 0.05) (Figures 2 and 3).

On the general health scale, patients in the low complications group scored an average of 6.2 points higher over time than patients in the high complication group after adjusting for age and sex (95\% CI 3.2, 9.3 and p value $<0.001$ ).

Patients in the low complication group had an average 3.5 points higher over time on Vitality when compared to patients in the high complication group, after adjusting for age and sex (95\% CI 0.35, 5.8 and p value $=0.03$ ).

In mental health, patients with low-grade complications scored better at baseline although this difference was not significant. Patients in the low compilations group scored an average of 6.1 points higher over time than patients in the high complication group after adjusting for age and sex (95\% CI 2.8, 9.5 and p value < 0.001). Of note that patients with the low-grade complications have better mental health scores at twelve weeks after surgery when compared to baseline assessment, this can be attributed to pre-operative anxiety and or depression that are associated with the new diagnosis of cancer and the upcoming surgical intervention at baseline assessment.

\subsection{HRQOL Measured by the EORTC QLQ 30 and QLQ 13}

Using the EORTC QLQ 30 and QLQ 13, differences in HRQOL post-operatively were noted at eight weeks after surgery in the high complication group compared to the no and low complications group (Figures 4 and 5 ). The differences were statistically significant in the following scales and symptoms; shoulder and chest pain, dyspnea scale, cognitive and emotional functioning, Insomnia and fatigue as well as financial difficulties (Table 3) lists the mean (SE) measured by the QLQ 30 and QLQ 13 questionnaires comparing the two complications group at baseline, two weeks and eight weeks from surgery. 
Table 2. SF-36 eight domains comparing the No/Low to high complications group at baseline, 4 weeks and 12 weeks from surgery. Mean (SE).

\begin{tabular}{|c|c|c|c|c|c|}
\hline SF-36 Scale & Complications & Baseline & 4 Week & 12 Week & p-Value ${ }^{*}$ \\
\hline Physical Functioning & $\begin{array}{l}\text { No/Low } \\
\text { Severe }\end{array}$ & $\begin{array}{c}73.2(4.5) \\
65.0(6)\end{array}$ & $\begin{array}{l}56.5(3.8) \\
50.3(7.0)\end{array}$ & $\begin{array}{l}71.6(3.9) \\
67.0(6.5)\end{array}$ & 0.06 \\
\hline Role Physical & $\begin{array}{l}\text { No/Low } \\
\text { Severe }\end{array}$ & $\begin{array}{l}74.7(5.9) \\
76.8(7.6)\end{array}$ & $\begin{array}{l}30.7(4.4) \\
28.3(8.7)\end{array}$ & $\begin{array}{l}60.2(6.5) \\
55.2(8.7)\end{array}$ & 0.3 \\
\hline Bodily Pain & $\begin{array}{l}\text { No/Low } \\
\text { Severe }\end{array}$ & $\begin{array}{l}76.3(4.9) \\
68.6(4.3)\end{array}$ & $\begin{array}{l}45.1(4.2) \\
51.7(7.4)\end{array}$ & $\begin{array}{l}71.7(7.1) \\
67.0(4.2)\end{array}$ & 0.1 \\
\hline Vitality & $\begin{array}{l}\text { No/Low } \\
\text { Severe }\end{array}$ & $\begin{array}{l}60.0(4.2) \\
59.2(4.8)\end{array}$ & $\begin{array}{l}46.1(3.2) \\
47.6(8.2)\end{array}$ & $\begin{array}{l}51.0(6.6) \\
47.5(4.8)\end{array}$ & 0.02 \\
\hline General Health & $\begin{array}{l}\text { No/Low } \\
\text { Severe }\end{array}$ & $\begin{array}{l}64.5(3.3) \\
68.5(4.4)\end{array}$ & $\begin{array}{l}67.0(3.8) \\
69.4(3.2)\end{array}$ & $\begin{array}{l}67.7(4.7) \\
58.9(4.2)\end{array}$ & $<0.01$ \\
\hline Social Functioning & $\begin{array}{l}\text { No/Low } \\
\text { Severe }\end{array}$ & $\begin{array}{l}79.0(4.1) \\
83.8(5.4)\end{array}$ & $\begin{array}{l}61.1(5.1) \\
62.5(10.2)\end{array}$ & $\begin{array}{l}75.9(5.5) \\
75.0(7.2)\end{array}$ & 0.09 \\
\hline Role Emotional & $\begin{array}{l}\text { No/Low } \\
\text { Severe }\end{array}$ & $\begin{array}{l}83.6(4.4) \\
86.3(5.4)\end{array}$ & $\begin{array}{l}82.0(4.0) \\
89.0(4.9)\end{array}$ & $\begin{array}{l}85.8(4.1) \\
82.7(9.0)\end{array}$ & 0.3 \\
\hline Mental Health & $\begin{array}{l}\text { No/Low } \\
\text { Severe }\end{array}$ & $\begin{array}{l}73.7 \text { (3.7) } \\
79.4(4.9)\end{array}$ & $\begin{array}{l}78.1(2.8) \\
76.5(6.2)\end{array}$ & $\begin{array}{l}85.4(4.1) \\
71.5(4.1)\end{array}$ & $<0.01$ \\
\hline
\end{tabular}

${ }^{*}$ p-value from GEE linear regression for differences in change over time between those with and without complications after adjusting for age and sex.

Table 3. QLQ 30/13 significant scales and symptoms at baseline, 2 weeks and 8 weeks after surgery comparing the two complications groups. Mean (SE).

\begin{tabular}{|c|c|c|c|c|c|c|}
\hline & QLQ 30/13 & Complications & Baseline & 2 Week & 8 Week & p-Value ${ }^{*}$ \\
\hline \multirow{3}{*}{$\frac{\mathscr{\Xi}}{\overparen{E}}$} & Dyspnea Scale & $\begin{array}{l}\text { No/Low } \\
\text { Severe }\end{array}$ & $\begin{array}{l}11.5(2.1) \\
16.3(3.6)\end{array}$ & $\begin{array}{l}19.0(3.2) \\
30.2(5.8)\end{array}$ & $\begin{array}{l}14.8(2.8) \\
22.2(1.8)\end{array}$ & $<0.01$ \\
\hline & $\begin{array}{l}\text { Cognitive } \\
\text { Functioning }\end{array}$ & $\begin{array}{l}\text { No/Low } \\
\text { Severe }\end{array}$ & $\begin{array}{l}86.9(2.8) \\
95.1(2.4)\end{array}$ & $\begin{array}{l}86.3(3.5) \\
84.5(5.9)\end{array}$ & $\begin{array}{l}89.7(5.5) \\
87.0(3.8)\end{array}$ & 0.02 \\
\hline & $\begin{array}{c}\text { Emotional } \\
\text { Functioning }\end{array}$ & $\begin{array}{l}\text { No/Low } \\
\text { Severe }\end{array}$ & $\begin{array}{l}79.5(3.5) \\
87.7(3.8)\end{array}$ & $\begin{array}{l}85.4(3.1) \\
81.5(7.3)\end{array}$ & $\begin{array}{l}89.7(3.5) \\
83.0(3.5)\end{array}$ & 0.02 \\
\hline \multirow{5}{*}{ 离 } & Chest Pain & $\begin{array}{l}\text { No/Low } \\
\text { Severe }\end{array}$ & $\begin{array}{l}27.4(6.2) \\
27.1(6.2)\end{array}$ & $\begin{array}{c}19.0(5.8) \\
31.0(10.2)\end{array}$ & $\begin{array}{l}20.5(7.1) \\
23.5(5.0)\end{array}$ & $<0.01$ \\
\hline & Shoulder Pain & $\begin{array}{l}\text { No/Low } \\
\text { Severe }\end{array}$ & $\begin{array}{l}16.0(4.2) \\
10.8(2.5)\end{array}$ & $\begin{array}{l}31.0(4.9) \\
42.3(7.0)\end{array}$ & $\begin{array}{l}11.5(2.9) \\
21.6(3.5)\end{array}$ & $<0.01$ \\
\hline & Insomnia & $\begin{array}{l}\text { No/Low } \\
\text { Severe }\end{array}$ & $\begin{array}{l}27.3(6.0) \\
9.80(4.8)\end{array}$ & $\begin{array}{l}21.4(8.3) \\
36.9(5.8)\end{array}$ & $\begin{array}{l}10.3(5.8) \\
27.1(5.3)\end{array}$ & $<0.01$ \\
\hline & Fatigue & $\begin{array}{l}\text { No/Low } \\
\text { Severe }\end{array}$ & $\begin{array}{l}21.4(3.5) \\
17.0(3.2)\end{array}$ & $\begin{array}{l}38.1(3.9) \\
43.7(7.9)\end{array}$ & $\begin{array}{l}26.7(3.3) \\
30.0(6.2)\end{array}$ & 0.03 \\
\hline & $\begin{array}{c}\text { Financial } \\
\text { Difficulties }\end{array}$ & $\begin{array}{l}\text { No/Low } \\
\text { Severe }\end{array}$ & $\begin{array}{l}6.00(3.0) \\
13.7(7.0)\end{array}$ & $\begin{array}{l}10.7(4.6) \\
26.2(9.4)\end{array}$ & $\begin{array}{l}11.1(4.3) \\
20.5(8.9)\end{array}$ & $<0.01$ \\
\hline
\end{tabular}

p-value from GEE linear regression for differences in change over time between those with and without complications after adjusting for age and sex.

\subsection{HRQOL Measured by the EQ-5D}

Compared to the no/low complications grade, patients with high-grade complications have statistically significant lower HRQOL measured by the EQ-5D VAS but this difference was not consistent over time. The health index did not determine any statistically significant difference between the no/low and high complications group at 2, 4 and 8 weeks after surgery. On average, patients in the low complication group had 0.014 points higher over time in the EQ-5D health index when compared to patients in the high complication group, after adjusting for age and sex (p-value 0.75 ); this difference is statistically not significant.

\section{Discussion and Conclusions}

We observed that an increasing severity of post-operative complications, as measured by the Clavien classification system, was associated with worsening HRQOL by several objective measures for up to three months 


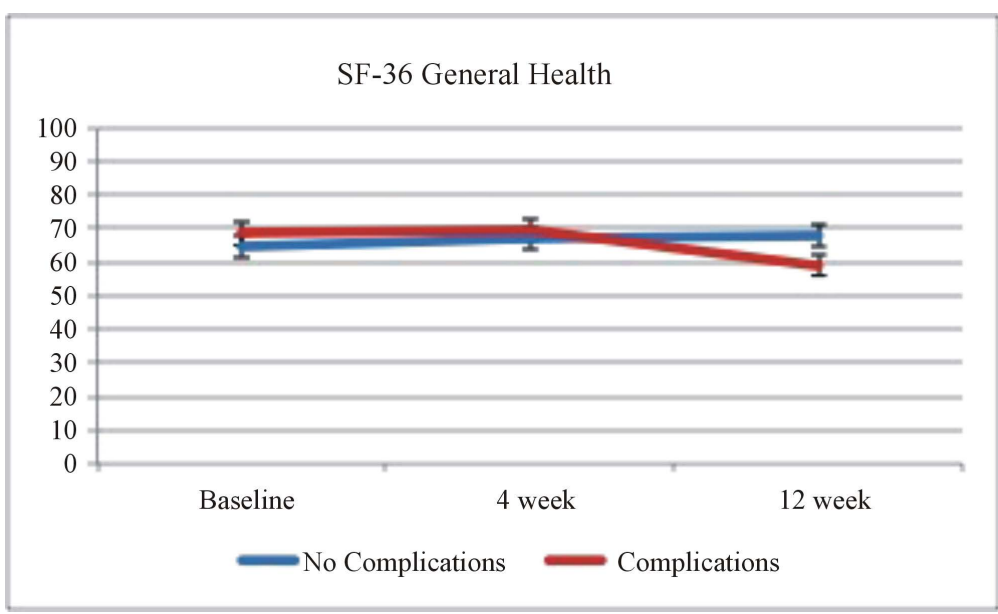

Figure 2. SF-36 general health comparing No/Low to high-grade complications groups.

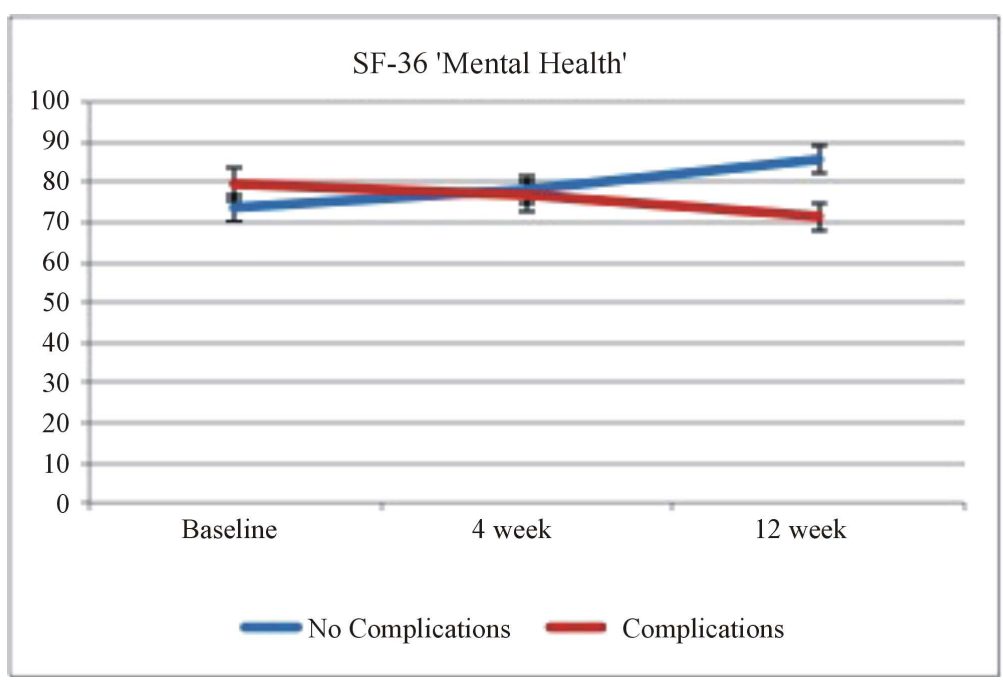

Figure 3. SF-36 Mental Health comparing No/Low to High complications groups.

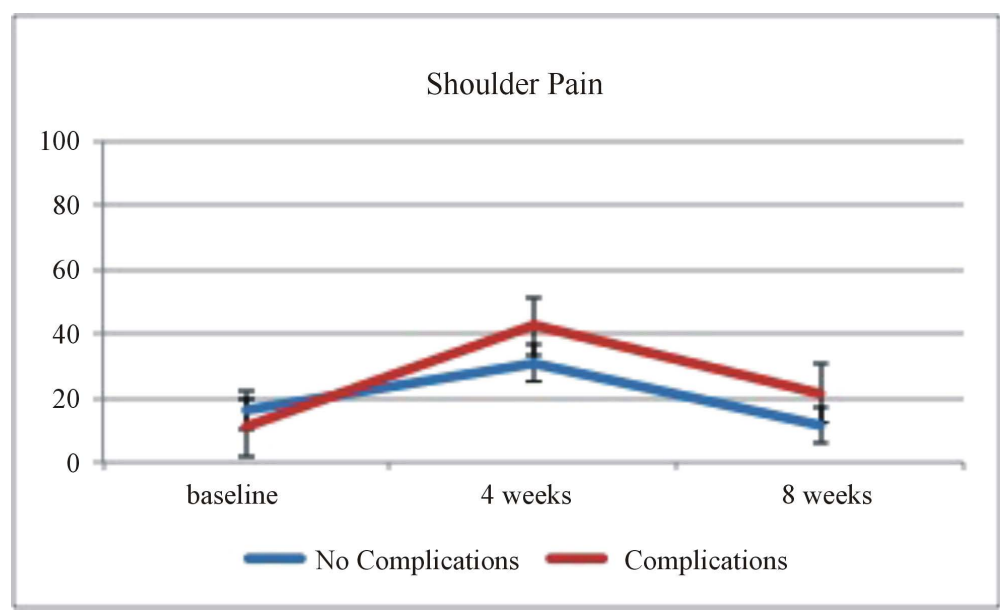

Figure 4. QLQ 13 shoulder pain comparing No/Low to high grade complications groups. 


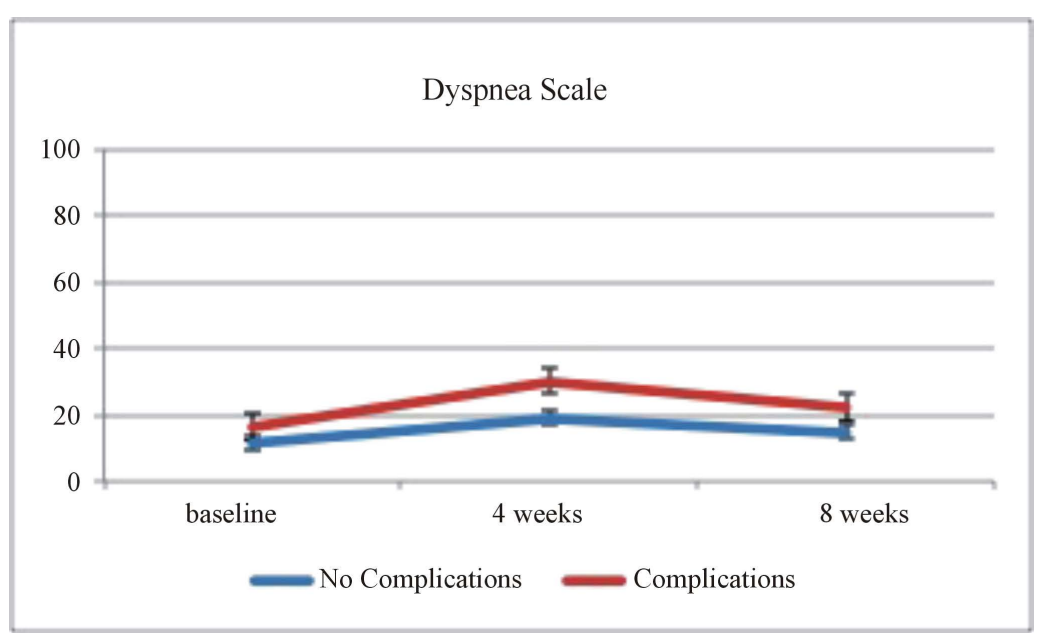

Figure 5. QLQ 13 dyspnea scale comparing No/Low to high grade complications groups.

following VATS lobectomy. General Health, Vitality and Mental Health were the main affected domains of the SF-36 generic measure at three months after surgery. Patients with more severe complications had significant decline in HRQOL at two months after surgery as measured by the disease specific measures (QLQ 30 and QLQ 13); these differences were mainly in symptoms like chest pain, shoulder pain, dyspnea, fatigue and insomnia which can lead to considerable decline in productivity and financial difficulties. While insomnia was noted to be worse at baseline in patients the low-grade complications, at two months after surgery a significant improvement was noted in this group, especially when compared to the high-grade complications group. This is likely to be related to anxiety associated with diagnosis before surgery and the overall complications status post-operatively.

The utility index from the EQ-5D measure did not detect any statistically significant difference between the high and no/low complications group over time after surgery; this could be explained in two ways. The first is because of the small sample size we used which was calculated based on the SF-36 measure, and the second reason is the possibility that the responsiveness of the EQ-5D in this patient population is limited in its ability to determine change over time. At baseline the EQ-5D health index Standard Deviation (SD) for the total sample was 0.08 . By using a $0.5 \mathrm{SD}$ (i.e., 0.04) as the minimal clinically important difference, we might consider the observed difference to be clinically important, and in favor of the No/Low complications groups, but lacking sufficient power to reach statistical significance.

Lobectomy is the most commonly performed procedure for the treatment of early stage and locally advanced lung cancer [18] [19]. The VATS approach for anatomical resection was introduced in the early 1990s and started to gain more popularity over the last few years [18] [20]. The early motivation for using the VATS procedure is the widespread assumption by thoracic surgeons that a more minimally invasive approach to lung cancer resection would reduce post-operative complications, hospital length of stay, shorten the recovery time to the preoperative heat state and have equivalent oncologic outcomes (recurrence and mortality) as compared to the traditional thoracotomy.

Many observational studies have reported on the superiority of VATS lobectomy when compared to the thoracotomy approach in terms of post-operative complications, length of stay, blood loss, post-operative pain and inflammatory response [20]-[23].

To our knowledge, no studies have assessed HRQOL based on post-operative complications in patients undergoing lobectomy for the treatment of NSCLC. In other indications, HRQOL has been shown to return to baseline function in six to twelve months after lobectomy thoracotomy and less than this time period in patients who underwent the VATS approach [3] [4] [10].

The strengths and limitations of this study are several. One of the main limitations is the observational nature of the study with its associated limitation of confounding and bias. In an attempt to decrease the risk of information bias, the outcome assessors were blinded to the presence and severity of complications that the patients had during their post-operative period (i.e. the individuals administrating the HRQOL instruments were not informed 
of the patients operative and post-operative hospital course a-priori of their administrating the HRQOL instruments).

Since the exposure of interest was post-operative complications and their severity, randomization is impossible, and differences in length of stay and chest tube duration were encountered between the high and no/low complications groups. Other limitations would be the small sample size, the possible confounding effect of other factors (tumor stage and grade, pulmonary function tests, operative time and intra-operative blood loss) and the fact that only one center was included in this study which can limit the external validity of the study.

On the other hand, some of the strengths of this study include the low percentage of patients who were lost to follow up (7\%) (two from the no/low complications group and one from the high complication group). Other strengths include the assessment of post-operative complications and HRQOL by a research team completely independent from the clinical team caring for this patient population, the small group of surgeons experienced with VATS resection for lung cancer, the use of the Clavien system which has been shown to be valid in thoracic surgery, and the robustness of the GEE analysis that incorporate change over time between and within individuals.

Surgeons and other physicians caring for patients undergoing VATS lobectomy for lung cancer are often more concerned about post-operative complications, however, patients frequently ask about the changes they can expect post-operatively and the impact of these changes on their life. The severity of post-operative complications can determine the HRQOL in patients undergoing VATS lobectomy up to three months after surgery. This information can be critical in pre-operative patient counseling.

\section{Acknowledgements}

The Royal Alexandra Hospital Foundation and a research grant from Johnson and Johnson pharmaceutical funded this study. JAJ is a Centennial Professor at the University of Alberta and holds a Senior Scholar Award with Alberta Innovates-Health Solutions (AIHS). Study data were collected and managed using REDCap electronic data capture tools hosted at the University of Alberta [24].

\section{References}

[1] Sugimura, H. and Yang, P. (2006) Long-Term Survivorship in Lung Cancer: A Review. Chest, 129, 1088-1097.

[2] Ginsberg, R.J. and Rubinstein, L.V. (1995) Randomized Trial of Lobectomy versus Limited Resection for T1 N0 NonSmall Cell Lung Cancer. Lung Cancer Study Group. The Annals of Thoracic Surgery, 60, 615-623. http://dx.doi.org/10.1016/0003-4975(95)00537-U

[3] Brunelli, A., Socci, L., Refai, M., Salati, M., Xiume, F. and Sabbatini, A. (2007) Quality of Life before and after Major Lung Resection for Lung Cancer: A Prospective Follow-Up Analysis. The Annals of Thoracic Surgery, 84, 410-416. http://dx.doi.org/10.1016/j.athoracsur.2007.04.019

[4] Ilonen, I.K., Rasanen, J.V., Knuuttila, A., Sihvo, E.I., Sintonen, H., Sovijarvi, A.R., et al. (2010) Quality of Life Following Lobectomy or Bilobectomy for Non-Small Cell Lung Cancer, a Two-Year Prospective Follow-Up Study. Lung Cancer (Amsterdam, Netherlands), 70, 347-351.

[5] Handy Jr., J.R., Asaph, J.W., Douville, E.C., Ott, G.Y., Grunkemeier, G.L. and Wu, Y.X. (2010) Does Video-Assisted Thoracoscopic Lobectomy for Lung Cancer Provide Improved Functional Outcomes Compared with Open Lobectomy? European Journal of Cardio-Thoracic Surgery, 37, 451-455.

[6] Ivanovic, J., Al-Hussaini, A., Al-Shehab, D., Threader, J., Villeneuve, P.J., Ramsay, T., Maziak, D.E., Gilbert, S., Shamji, F.M., Sundaresan, S. and Seely, A.J.E. (2011) Evaluating the Reliability and Reproducibility of the Ottawa Thoracic Morbidity and Mortality Classification System. The Annals of Thoracic Surgery, 91, 387-393. http://dx.doi.org/10.1016/j.athoracsur.2010.10.035

[7] Dindo, D., Demartines, N. and Clavien, P.A. (2004) Classification of Surgical Complications. A New Proposal with Evaluation in a Cohort of 6336 Patients and Results of a Survey. Annals of Surgery, 240.

[8] Nicastri, D.G., Wisnivesky, J.P., Litle, V.R., Yun, J., Chin, C., Dembitzer, F.R. and Swanson, S.J. (2008) Thoracoscopic Lobectomy: Report on Safety, Discharge Independence, Pain, and Chemotherapy Tolerance. Journal of Thoracic and Cardiovascular Surgery, 135, 642-647. http://dx.doi.org/10.1016/j.jtcvs.2007.09.014

[9] Hopman, W.M., Towheed, T., Anastassiades, T., Tenenhouse, A., Poliquin, S., Berger, C., Joseph, L., Brown, J.P., Murray, T.M., Adachi, J.D., Hanley, D.A., Papadimitropoulos, E. and the Canadian Multicenter Osteoporosis Study Research Group (2000) Canadian Normative Data for the SF-36 Health Survey. CMAJ, 163, 265-271.

[10] Baysungur, V., Tezel, Ç., Okur, E., Demirhan, R., Kutlu, B. and Halezeroğlu, S. (2011) Quality of Life Assessment Six 
Months after Lobectomy for Lung Cancer: Video-Assisted Thoracoscopic Surgery versus Thoracotomy. Turkish Journal of Thoracic and Cardiovascular Surgery, 19, 207-212.

[11] Brunelli, A., Socci, L., Refai, M., Salati, M., Xiume, F. and Sabbatini, A. (2007) Quality of Life before and after Major Lung Resection for Lung Cancer: A Prospective Follow-Up Analysis. The Annals of Thoracic Surgery, 84, 410-416. http://dx.doi.org/10.1016/j.athoracsur.2007.04.019

[12] Hays, R.D., Prince-Embury, S. and Chen, H. (1998) RAND-36 Health Status Inventory. Psychological Corp, San Antonio.

[13] EORTC 2011 Manual (2011) By the European Organization for Research and Treatment of Cancer.

[14] Rabin, R. and de Charro, F. (2001) EQ-5D: A Measure of Health Status from the EuroQol Group. Annals of Medicine, 33, 337-343. http://dx.doi.org/10.3109/07853890109002087

[15] Shaw, J.W., Johnson, J.A. and Coons, S.J. (2005) US Valuation of the EQ-5D Health States: Development and Testing of the D1 Valuation Model. Medical Care, 43, 203-220. http://dx.doi.org/10.1097/00005650-200503000-00003

[16] Luo, N., Johnson, J.A., Shaw, J.W. and Coons, S.J. (2007) A Comparison of the EQ-5D Index Scores Derived from the US and UK Population-Based Scoring Functions. Medical Decision Making, 27, 321-326. http://dx.doi.org/10.1177/0272989X07300603

[17] Norman, G.R., Sloan, J.A. and Wyrwich, K.W. (2003) Interpretation of Changes in Health-Related Quality of Life, the Remarkable Universality of Half a Standard Deviation. Medical Care, 41, 582-592. http://dx.doi.org/10.1097/01.MLR.0000062554.74615.4C

[18] Boffa, D.J., Allen, M.S., Grab, J.D., Gaissert, H.A., Harpole, K.H. and Wright, C.D. (2008) Data from the Society of Thoracic Surgeons General Thoracic Surgery Database: The Surgical Management of Primary Lung Tumors. The Journal of Thoracic and Cardiovascular Surgery, 135, 247-254. http://dx.doi.org/10.1016/j.jtcvs.2007.07.060

[19] Little, A.B., Rusch, V.W., Bonner, J.A., Gaspar, L.E., Green, M.R., Web, W.R. and Stewart, A.K. (2005) Patterns of Surgical Care of Lung Cancer Patients. The Annals of Thoracic Surgery, 80, 2051-2056. http://dx.doi.org/10.1016/j.athoracsur.2005.06.071

[20] McKenna, R.J., Houck, W. and Fuller, C.B. (2006) Video-Assisted Thoracic Surgery Lobectomy: Experience with 1100 Cases. The Annals of Thoracic Surgery, 81, 421-426. http://dx.doi.org/10.1016/j.athoracsur.2005.07.078

[21] Sugiura, H., Morikaw, T., Kaji, M., Sasmura, Y., Kondo, S. and Katoh, H. (1999) Long-Term Benefits for the Quality of Life after Video-Assisted Thoracoscopic Lobectomy in Patients with Lung Cancer. Surgical Laparoscopy Endoscopy \& Percutaneous Techniques, 9, 403-410. http://dx.doi.org/10.1097/00129689-199912000-00007

[22] Ng, C.S.H., Wan, S., Hui, C.W.C., Wan, I.Y.P., Lee, T.W., Underwood, M.J. and Yim, A.P. (2007) Video Assisted Thoracic Surgery Lobectomy for Lung Cancer Is Associated with Less Immunochemokine Disturbances than Thoracotomy. European Journal Cardio-Thoracic Surgery, 31, 83-87. http://dx.doi.org/10.1016/j.ejcts.2006.10.019

[23] Cattaneo, S.M., Park, B.J., Wilton, A.S., Seshan, V.E., Bains, M.S., Downey, R.J., Flores, R.M., Rizk, N. and Rusch, V.W. (2008) Use of Video-Assisted Thoracic Surgery for Lobectomy in the Elderly Results in Fewer Complications. The Annals of Thoracic Surgery, 85, 231-236. http://dx.doi.org/10.1016/j.athoracsur.2007.07.080

[24] Harris, P.A., Taylor, R., Thielke, R., Payne, J., Gonzalez, N. and Conde, J.G. (2009) Research Electronic Data Capture (REDCap)-A Metadata-Driven Methodology and Workflow Process for Providing Translational Research Informatics Support. Journal of Biomedical Informatics, 42, 377-381. http://dx.doi.org/10.1016/j.jbi.2008.08.010 